\title{
Transvaginal Repair of Vesico Vaginal Fistula: A 10-Year Experience with Analysis of Factors Affecting Outcomes
}

\author{
Manoj Kumar Samarth Agarwal Apul Goel Ashish Sharma Ajay Agarwal \\ Siddharth Pandey Satya Narain Sankhwar \\ Department of Urology, King George's Medical University, Lucknow, India
}

\section{Keywords}

Transvaginal repair · Vesicovaginal fistula $\cdot$ Outcomes

\begin{abstract}
Objectives: To highlight the transvaginal route as an excellent approach for repair of a simple trigonal, supra-trigonal vesico-vaginal and urethrovaginal fistulae without compromising on the successful patient outcomes. We also determine factors affecting outcomes in such patients. Materials and Methods: A retrospective analysis was carried out on 58 patients with simple trigonal, supra trigonal and urethrovaginal fistula who underwent transvaginal repair in the last 10 years. Simple fistulas were defined as fistula less than $3 \mathrm{~cm}$ in size or recurrent fistulae less than $1.5-2 \mathrm{~cm}$ in size and located either supra-trigonally (above the bar of mercier) or sub-trigonally (below the bar of mercier) as determined by cystoscopy. Results: Obstetric cause, due to ob-
\end{abstract}

structed labour, was the most common cause of fistula formation (68.96\%), while remaining (29.31\%) were attributed to hysterectomy. Primary fistulae were found in $68.9 \%$ of patients and recurrent fiistulae in $31.1 \%$ patients. The mean age of patients was 33.4 years. Average fistula size was 1.5 $\mathrm{cm}$. The success rate of primary operation was $84.12 \%$ (50/58). On using a multivariate regression model, the underlying aetiology (OR 2.2), fistula location (OR 2.5) and history of previous repair (OR 2.4) were found to be significant factors affecting outcome. Conclusion: The transvaginal approach is less invasive and achieves comparable success rates as compared to other methods of vesico-vaginal fistula repair. This surgery with Foley catheter has a high success rate with reduced morbidity. We postulate that vaginal approach should be preferred over abdominal approach for repair of all vaginally accessible vesico vaginal fistulae, both of obstetrical and gynaecological origin.

(c) 2019 S. Karger AG, Basel

\section{KARGER}

E-Mail karger@karger.com

www.karger.com/uin
(C) 2019 S. Karger AG, Basel Dr. Samarth Agarwal

Department of Urology

King George's Medical University

Lucknow, Uttar Pradesh 226003 (India)

E-Mail rebellite@gmail.com 


\section{Introduction}

Vesico vaginal fistula (VVF) is a common occurrence in developed countries with an annual incidence of $50,000-100,000$ cases and more than 2 million women affected worldwide [1].

While obstructed or prolonged labour continues to be the leading cause in developing countries, iatrogenic injury during obstetric or gynaecologic surgery such as caesarean section or hysterectomy is the most common cause in the industrialized world [2].

VVF is a debilitating condition that leads to persistent foul odour with urinary discharge leading to excoriation of vulva and vagina. In a developing country like India, where strong religious and cultural beliefs are pertinent in almost every sphere of human life, this causes a lot of social taboos leading to social isolation and physical and emotional distress of the patients.

There is currently no gold standard technique for the management of a simple VVF. Traditionally fistula repair was carried out by either transabdominal or transvaginal approach with success rates ranging from 50 to $100 \%$ [3].

Trendelenburg described transabdominal repair, which had become the standard of care for difficult VVFs. Around the mid-19th century, James Sims described his technique of a transvaginal approach with the use of silver sutures and bladder drainage postoperatively. While both transabdominal and transvaginal route have equivalent success rates, the transvaginal approach offers the advantage of avoiding a laparotomy, shorter hospital stay, minimal blood loss and rapid recovery [4-6].

Now newer techniques have also been described including laparoscopic and robotic approaches for repair of VVF, depending on the skill and expertise of the surgeon [7]. However, these procedures involve the use of proper infrastructure, trained manpower and OT personnel, high costs and considerable learning curve, which tantamount to an additional financial burden on the healthcare of a developing country.

Couvelaire in 1953 described the keys to successful repair of VVF as "good visualization, good approximation of margins, good dissection and drainage" [8].

Transvaginal repair of VVFs has now been carried out at our institution in the last 10 years owing to a multitude of advantages. The aim of this study is to highlight transvaginal route as an excellent approach for repair of a simple trigonal, supra-trigonal vesico-vaginal and urethrovaginal fistulae without compromising on the successful patient outcomes. We also determine factors affecting outcomes in such patients.

Transvaginal VVF Repair Outcomes

\section{Materials and Methods}

A retrospective analysis was carried out on 58 patients with simple trigonal, supra trigonal and urethrovaginal fistula who underwent transvaginal repair in the last 10 years between 2007 and 2017 at the Department of Urology at King George's Medical University. Approval and Ethical clearance was taken from Institutional Review Board.

Simple fistulas were defined as fistula less than $3 \mathrm{~cm}$ in size or recurrent fistula less than $1.5-2 \mathrm{~cm}$ in size and located either supratrigonally (above the bar of mercier) or sub-trigonally (below the bar of mercier) as determined by cystoscopy. Urethrovaginal fistulas were also included. All fistulas at a distance less than $1 \mathrm{~cm}$ form ureteric orifice were stented with ureteric catheters. All fistulas involving any of the ureteric orifices requiring reimplantation, bladder neck fistulas, ureterovaginal fistula, vesico-uterine fistula, fistula after radiotherapy/malignancy, diabetes and hypertensive patients were excluded.

All patients were evaluated preoperatively by history, physical examination, serum creatinine, ultrasonography abdomen and intravenous urography. A cystoscopy was performed and the following details were noted - the location, size and numbers of the fistulas, distance from the ureteric orifices, condition of the mucosa around the fistulous opening, thickness of fistulous septum (assessed by inserting a finger trans-vaginally while performing cystoscopy and palpating the fistula). Three swab test with methylene blue was done wherever the diagnosis was uncertain. Vaginal speculum examination was done to assess the vaginal capacity and vaginal mucosal integrity. For all practical purposes, a vagina admitting 3 fingers comfortably was considered adequate. Around 30 patients with urinary tract infection were treated with antibiotics for 2 weeks preoperatively.

The primary repair of fistula was delayed by at least 6 weeks to provide sufficient time for infection and inflammation to subside. The recurrent fistulas were repaired after 3 months. In the pre op period, vaginal douching with betadine was done $48 \mathrm{~h}$ before the surgery. In the post op period, a betadine pack was kept and it was removed after $24 \mathrm{~h}$

\section{Surgical Technique}

A preopoerative cystoscopy was done, in the lithotomy position, fistula identified and guide wire was placed and secured in the fistulous opening. The patient was then positioned as shown in Figures 1 and 2.

The patient is placed prone in reverse lithotomy position with slight head low tilt. A bolster is placed below the perineum as shown in the figure and this makes working in depth easier. The knee is flexed at 90 degrees and adequately padded with leg stirrups. A Foley catheter is then inserted through the fistulous opening and around $5 \mathrm{~mL}$ air injected to fix it in the bladder. We routinely used a 12Fr Foley for fistulous opening less than $1 \mathrm{~cm}$ in size and 14Fr Foley for larger fistulas. Once Foley was fixed, a gentle traction is applied; this clearly brings the fistulous orifice in the operating field. Gentle traction on this catheter also helps to expose even the highest vaginal vault fistula and facilitates dissection. The tissues are then infiltrated with 1:200,000 solution of adrenaline to demarcate tissue planes and prevent oozing. The vaginal wall is then dissected all around approximately $5 \mathrm{~mm}$ away from the fistulous orifice. Adequate mobilization of vagina from the underlying bladder ensures tension-free closure. The bladder wall is then 


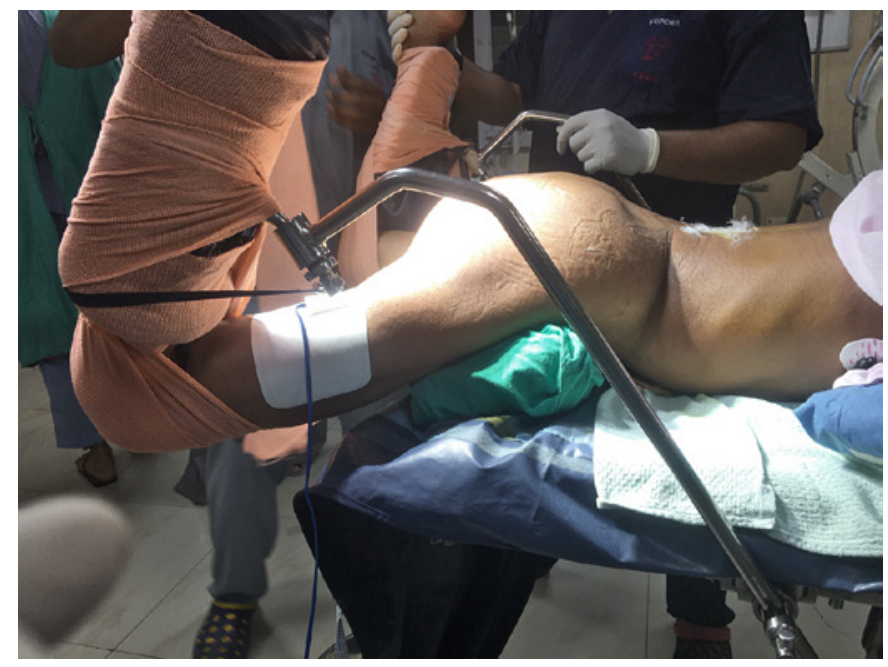

Fig. 1. The prone position used for repair of all transvaginal VVF (note the padding and perineal bolster support).

repaired in 2 layers with vicryl 3-0. The vaginal wall is closed with $2-0$ vicryl suture in a continuous fashion.

Of the 2 standard techniques, namely, the Latzko procedure and vaginal flaps techniques, we commonly employ the Martius Flap as a cover over the fistula repair. In patients with recurrent fistula, we use Martius flap cover from the opposite side. Also, if the single labial fat pad did not provide adequate coverage, we use the opposite side flap. Still in certain cases where Martius flap was not available, we used a peritoneal flap.

In all our repairs, we perform a tension-free and water-tight closure with avoidance of overlapping suture lines and without excision of the fistulous tract. This is in contrast to the abdominal approach wherein excision of fistulous tract unnecessarily enlarges the defect and potentiates ureteral injury.

A healthy vascularized Martius flap interposition was done between the bladder and vagina. The bladder was drained with per urethral catheter only in all patients for 2 weeks postoperatively. The same principles also applied to the repair of urethrovaginal fistulae.

\section{Statistical Analysis}

Chi-square test was used to analyse the data using graph pad software. Association between 2 variables was found statistically significant if $p$ value was $<0.05$.

\section{Results}

The results are shown in Table 1 and 58 cases of VVF were managed transvaginally during the study period. Of these, obstetric cause was the most common cause of fistula formation $68.96 \%$ (40 out of 58 ), while $29.31 \%$ (17 of 58) were attributed to hysterectomy due to either laparoscopic or open approach. Among the obstetric causes, obstructed labour was the most common cause of fistula for-

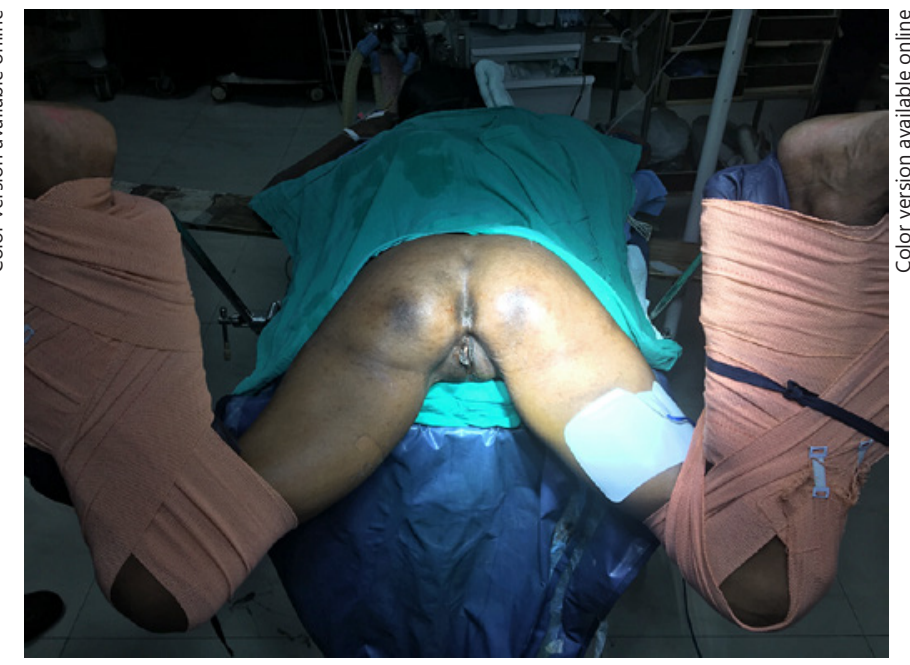

Fig. 2. The final prone positioning in all transvaginal VVF repair (front view).

Table 1. Results

\begin{tabular}{|c|c|}
\hline Variables & Number of patients \\
\hline Age, years, median (range) & $33.4(19-57)$ \\
\hline \multicolumn{2}{|l|}{ Location of fistula } \\
\hline Supratrigonal & 15 \\
\hline Subtrigonal & 35 \\
\hline Urethrovaginal & 8 \\
\hline \multicolumn{2}{|l|}{ Size of fistula, $\mathrm{cm}$} \\
\hline $0.5-1$ & 20 \\
\hline $1-2$ & 30 \\
\hline $2-3$ & 8 \\
\hline \multicolumn{2}{|l|}{ Multiplicity } \\
\hline Single & 52 \\
\hline Multiple & 6 \\
\hline \multicolumn{2}{|l|}{ Type of fistula } \\
\hline Primary & 40 \\
\hline Recurrent & 18 \\
\hline \multicolumn{2}{|l|}{ Etiology } \\
\hline \multicolumn{2}{|l|}{ Obstetric } \\
\hline Caesarean & 19 \\
\hline \multicolumn{2}{|l|}{ Difficult vaginal delivery due } \\
\hline to obstructed labour & 21 \\
\hline \multicolumn{2}{|l|}{ Hysterectomy } \\
\hline Lap & 5 \\
\hline Open & 12 \\
\hline Trauma & 1 \\
\hline \multicolumn{2}{|l|}{ Flap interposition } \\
\hline Maritus & 48 \\
\hline Peritoneal & 7 \\
\hline \multicolumn{2}{|l|}{ Ureteric stents } \\
\hline Yes & 20 \\
\hline No & 38 \\
\hline
\end{tabular}


mation. All were simple fistulae. While $31.1 \%$ were recurrent fistule, $68.9 \%$ (40 out of 58) were primary fistulae.

The mean age of patients was 33.4 years. Average fistula size was $1.5 \mathrm{~cm}$. All were single fistulae except 6 , which were double and all repaired trans vaginally. Ureteric stents were used in 20 patients owing to closeness of fistula to ureteric orifice. Maritus fat pad was interposed in 48 patients and peritoneal flap in 7 patients. Three cases were repaired without any flap interposition.

The mean operative time was $78 \pm 18.1 \mathrm{~min}$, and ranged from 60 to $100 \mathrm{~min}$. Mean blood loss was $65 \pm 13.4 \mathrm{~mL}$ (range $50-90 \mathrm{~mL}$ ). The mean postoperative hospitalization time was $8 \pm 3.8$ days (range $7-13$ days). No intraoperative complications were observed. The success rate of primary operation was $84.12 \%$ (50/58). Transvaginal repair failed in 8 patients.

In a univariate analysis, the underlying aetiology, fistula location, presence of UTI and history of previous repair had a significant impact on surgery outcomes as shown in Table 2. On using a multivariate regression model, the underlying aetiology (OR 2.2), fistula location (OR 2.5) and history of previous repair (OR 2.4) were found to be significant factors affecting outcome.

\section{Discussion}

VVFs are an emotionally distressing postoperative complication that has serious social and quality-of-life implications. While Obstetric VVF continues to occur in developing countries due to ignorance and inadequate medical facilities, it is uncommon in the western world. Obstetric causes include injury at the time of caesarean section, forceps delivery and obstructed labour $[9,10]$. In our study, almost $70 \%$ patients had fistula due to obstetric causes and the remaining had fistula due to hysterectomy.

Various methods of genital fistula repairs have been described. Literature is robust with transabdominal, transvaginal, laparoscopic and robotic approaches of VVF repair and yet none is considered to be the "best" [11-13]. The most important factor is the preference and experience of the surgeon although adjuvant factors like size, location and history of previous surgeries have an impact on the choice of approach [14]. In our series also, we found these factors important in affecting the outcome.

The transvaginal route is now the preferred route of fistula approach at our institution. Plenty of patients now prefer vaginal approach to abdominal laparotomy. Abdominal repair is performed transvesically and there is an
Table 2. Analysis of local variable affecting transvaginal VVF repair

\begin{tabular}{|c|c|c|c|}
\hline Variables & $\begin{array}{l}\text { Successful } \\
\text { repair }\end{array}$ & $\begin{array}{l}\text { Failed } \\
\text { repair }\end{array}$ & $p$ value \\
\hline Etiology & & & $0.023^{*}$ \\
\hline Obstetrical & 35 & 5 & \\
\hline Non obstetrical & 14 & 3 & \\
\hline Fistula size, $\mathrm{cm}$ & & & 0.231 \\
\hline $0.5-1$ & 17 & 3 & \\
\hline $1-2$ & 26 & 4 & \\
\hline $2-3$ & 7 & 1 & \\
\hline Fistula location & & & $0.0012^{*}$ \\
\hline Supratrigonal & 10 & 2 & \\
\hline Subtrigonal & 33 & 4 & \\
\hline Urethrovaginal & 7 & 2 & \\
\hline Urinary tract infection & & & $0.03^{*}$ \\
\hline Yes & 30 & 5 & \\
\hline No & 28 & 3 & \\
\hline \multicolumn{4}{|l|}{ Previous repair } \\
\hline Yes & 15 & 3 & $<0.05^{*}$ \\
\hline No & 35 & 5 & \\
\hline \multicolumn{4}{|l|}{ Flap interposition } \\
\hline Yes & 48 & 7 & 0.48 \\
\hline No & 3 & 1 & \\
\hline \multicolumn{4}{|l|}{ Ureteric stents } \\
\hline Yes & 20 & 4 & 0.23 \\
\hline No & 38 & 4 & \\
\hline
\end{tabular}

inherent increased morbidity associated with a cystotomy and bowel manipulation. Also, as the bladder is opened, there are increased bladder spasms and discomfort postoperatively. The vaginal approach is a less invasive approach. There is decreased requirement of analgesics, allows high cure rate, shorter hospital stay, relatively lower costs and does not require sophisticated or expensive material, dedicated OTs and infrastructure as needed for laparoscopic or robot-assisted repairs [15]. There is also an obvious advantage of cosmetic difference. We even repaired non-complex supra-trigonal fistulas with a success rate of $80 \%$. Operating such high lying fistula is easily possible trannsvaginally with our technique described earlier.

Repair of VVF can be a difficult surgical challenge that may require the interposition of various tissue flaps and grafts to buttress the repair. The Martius flap is an excellent flap and can be viewed as the vaginal equivalent of the omentum used in transabdominal repair. Other flaps that can be harvested to buttress the repair of complex 
VVF include peritoneal, labial and gluteal muscle flaps [16-18]. We used Martius flap in 48 patients and peritoneal flap in 7 patients. Also, in all our cases of urethrovaginal fistula, we used Martius flap, which could be easily harvested.

Many people argue about the potential problem of fistula exposure during transvaginal repair. We have found that all simple VVF, regardless of location, are amenable to vaginal repair and adjunctive procedures. This was also elaborated by Rajamaheswari et al. [19] who advocated that 3/4th gynaecological supra-trigonal VVF can be repaired vaginally in first attempt with a success rate comparable to that of the abdominal approach.

The advantages of our technique are innumerable. While exposing the bladder and perivesical fascia and creating vaginal wall flaps, high-lying fistulae can be easily approached by inserting a catheter into the fistulous tract and applying gentle downward traction. This approach also improves visualization of the structured layers of the fistula orifice, which is beneficial for the excision of scar tissue surrounding the fistula orifice. Suturing can also be performed with no tension and good hemostasis. It is acceptable to repeat the repair through a vaginal approach even after a first vaginal or transabdominal failure or vice versa.

\section{Conclusion}

The transvaginal approach is less invasive and achieves comparable success rates as compared to other methods of VVF repair. Genital fistula repair surgery with Foley catheter has a high success rate, reduced morbidity, minimal blood loss and short hospital stay. We postulate that vaginal approach should be preferred over abdominal approach for repair of all vaginally accessible VVF, both of obstetrical and gynaecological origin.

\section{Disclosure Statement}

The authors declare that they have no conflicts of interest to disclose.

\section{Financial Support}

The authors declare that this study has received no financial support.

\section{Informed Consent}

Informed consent was received from the patient.

\section{References}

1 Ahmed S, Genadry R, Stanton C, Lalonde AB. Dead women walking: neglected millions with obstetric fistula. Int J Gynaecol Obstet. 2007 Nov;99 Suppl 1:S1-3.

2 Miller EA, Webster GD. Current management of vesicovaginal fistulae. Curr Opin Urol. 2001 Jul;11(4):417-21.

3 Wong MJ, Wong K, Rezvan A, Tate A, Bhatia NN, Yazdany T. Urogenital fistula. Female Pelvic Med Reconstr Surg. 2012 Mar-Apr; 18(2):71-8

4 Blaivas JG, Heritz DM, Romanzi LJ. Early versus late repair of vesicovaginal fistulas: vaginal and abdominal approaches. J Urol. 1995 Apr;153(4):1110-2.

5 Dupont MC, Raz S. Vaginal approach to vesicovaginal fistula repair. Urology. 1996 Jul; 48(1):7-9.

$6 \mathrm{Sims} \mathrm{JM.} \mathrm{On} \mathrm{the} \mathrm{treatment} \mathrm{of} \mathrm{vesico-vaginal}$ fistula. Am J Med Sci. 1852;23:59-82.

7 Hemal AK, Kolla SB, Wadhwa P. Robotic reconstruction for recurrent supratrigonal vesicovaginal fistulas. J Urol. 2008 Sep;180(3): 981-5.

8 Couvelaire R. [Reflections on a personal statistics of 136 vesicovaginal fistulas]. J Urol Medicale Chir. 1953;59(3-4):150-60.
9 Blaivas JG, Heritz DM, Romanzi LJ. Early versus late repair of vesicovaginal fistulas: vaginal and abdominal approaches. J Urol. 1995 Apr;153(4):1110-2.

10 Dalela D, Goel A, Shakhwar SN, Singh KM. Vesical calculi with unrepaired vesicovaginal fistula: a clinical appraisal of an uncommon association. J Urol. 2003 Dec;170(6 Pt 1): 2206-8.

11 Nesrallah LJ, Srougi M, Gittes RF. The O'Conor technique: the gold standard for supratrigonal vesicovaginal fistula repair [PubMed]. J Urol. 1999 Feb;161(2):566-8.

12 Otsuka RA, Amaro JL, Tanaka MT, Epacagnan E, Mendes JB Jr, Kawano PR, et al. Laparoscopic repair of vesicovaginal fistula. J Endourol. 2008 Mar;22(3):525-7.

13 Sundaram BM, Kalidasan G, Hemal AK. Robotic repair of vesicovaginal fistula: case series of five patients. Urology. 2006 May;67(5): 970-3.
14 Rovner ES (Wein J, Kavoussi LR, Novick AC, Partin AW, Peters CA, editors). "Urinary tract fistula," in Campbell-Walsh Urology. 9th ed. Philadelphia, Pa, USA: Saunders; 2007. pp. 2323-40.

15 Frohmüller H, Hofmockel G. [Transvaginal closure of vesicovaginal fistulas]. Urologe A. 1998 Jan;37(1):70-4.

16 Hodges AM. The Mitrofanoff urinary diversion for complex vesicovaginal fistulae: experience from Uganda. BJU Int. 1999 Sep;84(4): 436-9.

17 Arrowsmith S, Hamlin EC, Wall LL. Obstructed labor injury complex: obstetric fistula formation and the multifaceted morbidity of maternal birth trauma in the developing world. Obstet Gynecol Surv. 1996 Sep;51(9): 568-74.

18 Raz S, Bregg KJ, Nitti VW, Sussman E. Transvaginal repair of vesicovaginal fistula using a peritoneal flap. J Urol. 1993 Jul; 150(1):56-9.

19 Rajamaheswari N, Chhikara AB, Seethalakshmi K, Bail A, Agarwal S. Trans-vaginal repair of gynecological supratrigonal vesicovaginal fistulae: A worthy option! Urol Ann. 2012 Sep;4(3):154-7. 